\section{Revista Chilena \\ de Pediatría}

www.revistachilenadepediatria.cl

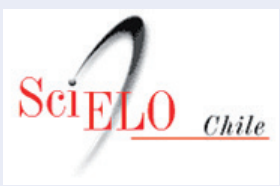

www.scielo.cl

\title{
Pandemia por nuevo Coronavirus: el amor en tiempos del Covid19
}

\section{Pandemic due to new Coronavirus: love in times of Covid19}

\author{
Jaime Rodríguez Troncoso ${ }^{\mathrm{a}}$
}

aPediatra Infectólogo. Unidad de Infectología Infantil, Clínica Alemana de Santiago, Chile

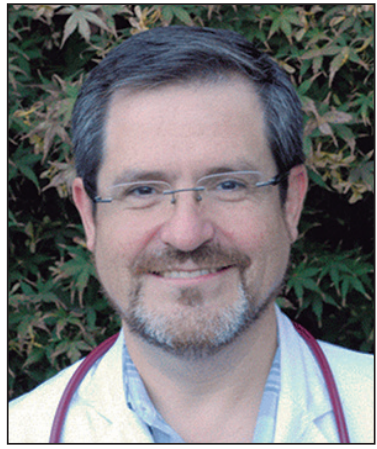

Los coronavirus son un grupo de virus RNA de la familia orthocoronaviridae, de amplia distribución en animales, cuyo nombre se debe a que en la microscopía electrónica semejan una pequeña corona. El primer coronavirus descubierto en seres humanos fue en la década del 60 del siglo XX por Tyrrell y Bynoe ${ }^{1}$, producía infecciones del tracto respiratorio, la mayoría de carácter leve. Excepcionalmente en niños menores de 2 años producen infecciones severas así como en algunos adultos susceptibles. La infección por coronavirus es de carácter zoonótica (se pueden contagiar de los animales a las personas) y se puede transmitir de persona a persona. Esto sabíamos hasta el 2018.

En Diciembre del 2019 casos de neumonía grave sin causa fueron detectados en Wuham, China, rápidamente se tomaron medidas para el control de la epidemia y se hicieron grandes esfuerzos en la identificación del agente. A fines de Enero del 2020 ya se había secuenciado el genoma completo de este nuevo coronavirus $^{2}$ y la OMS declaraba una emergencia internacional, ya en Marzo cerca de 200 países tenían la presencia de la enfermedad.

La pandemia actual de Covid19 producida por el recientemente denominado SARS Cov2, es la $3^{\text {a }}$ transmisión documentada de coronavirus de animales al hombre en 2 décadas. De acuerdo con estudios exhaustivos al respecto, sabemos que el SARS-CoV se transmitió de la civeta al ser humano y que se ha producido transmisión del MERS-CoV del dromedario al ser humano, ambos con una tasa de letalidad elevada, lograron ser controlados evitándose una pandemia. El SARS Cov2 tiene un origen cercano al coronavirus de murciélagos con un huesped intermediario aún desconocido.

En La Peste de Albert Camus se describe en detalles el arquetipo de un brote epidémico, en el libro Camus nos describe una ciudad activa, fea y monótona, en donde sus habitantes solo piensan en trabajar para enriquecerse y reservan los placeres mundanos para los escasos momentos de ocio de que disponen. Su ritmo de vida es frenético y rutinario. La peste avanza, desesperadamente se tratan de tomar medidas preventivas y de tratamiento, a pesar a ello hay muchas muertes y finalmente se destruye la actividad económica. Con la pandemia de Covid19 ha ocurrido algo similar, rápidamente difundida a través de redes sociales, cambió en forma drástica nuestra forma de relacionarnos, nuestra forma de trabajar, nuestras prioridades, desafiando nuestro tan preciado conocimiento científico y capacidad de respuesta, además ha puesto en jaque nuestra economía, creando una situación de vulneravilidad y temor generalizados. La gente busca explicaciones

\footnotetext{
Correspondencia:

Jaime Rodríguez Troncoso

jrodriguezt@alemana.cl

jaimerodriguezt@gmail.com 
frente a la epidemia : científicas, médicas, espirituales, apocalípticas. ¿Cómo expresamos nuestro cariño a más de un metro de distancia?

En pleno siglo 21 el genoma secuenciado nos permitió en tiempo record tener test diagnósticos confiables (reacción de polimerasa en cadena) y poder aprender más de esta enfermedad, sabemos que hay presencia del virus en secreciones respiratorias, deposiciones, sangre, saliva y orina, que se puede excretar por el aparato respiratorio por 2 semanas $^{3}$ y por deposiciones hasta 5 semanas. Hay presencia viral en pacientes asintomáticos u oligo sintomáticos (incluso en cantidades importantes) y conocemos la duración en el ambiente: puede permanecer 2 a $3 \mathrm{~h}$ en secreciones respiratorias, $24 \mathrm{~h}$ en superficies de cartón, $2 \mathrm{~h}$ en cobre, y hasta 3 días en acero y plástico ${ }^{4}$. El período de incubación va entre 1 a 14 días. Hasta ahora sabemos que los niños pequeños se ven afectados con cuadros clínicos más leves o asintomáticos y con menos letalidad que adultos mayores con comorbilidades, sin embargo como ocurre con otras enfermedades como en hepatitis A, presentan una alta excreción viral, lo que los convierte en muy buenos diseminadores.

Sin embargo a pesar de nuestros adelantos científicos la pandemia ha logrado progresar a una gran velocidad. El número básico de reproducción (R0) define el número medio de casos secundarios generados por un caso primario. Esto ocurre cuando la población es en gran medida susceptible a la infección. Así, se determina el número total de personas que probablemente estén infectadas, tomando esto en cosideración, para que se produzca una epidemia, el valor R0 debe ser mayor que uno. Por ejemplo, el sarampión, el R0 se estima en alrededor de 15. Para el coronavirus, la estimación de R0 está en alrededor del 2,5. A medida que avanza una epidemia, el número de reproducción efectiva (R) disminuye. En Chile se ha estimado con estos antecedentes que con un R0 de 1,5 a 2,35 tendremos el pico de casos entre la $7^{\mathrm{a}}$ y $8^{\mathrm{a}}$ semana del brote, con la mayor demanda de camas de cuidados intensivos ${ }^{5}$.
Dentro de los factores que contribuyen a esta fácil diseminación están: la resistencia del virus en el ambiente, las infecciones no documentadas ${ }^{6}$, la falta de tratamiento efectivo, la presencia de superdiseminadores, la falta de medidas adecuadas en salud pública o su implementación tardía y que toda la población es susceptible. A la fecha varios tratamientos se han ensayado como terapia de rescate con resultados variables y probados en grupos pequeños de pacientes, medicamentos como cloroquina o hidroxicloroquina, el Tocilizumab como inhibidor del receptor de IL6 en pacientes con gran compromiso inflamatorio y tormenta de citoquinas, antivirales como el Remdesivir muestran resultados prometedores en casos severos. Por ahora nuestros esfuerzos se concentran en lograr contener la infección a través de enérgicas medidas de contención como cuarentena, cordones sanitarios, aislamiento social etc. y tratar de evitar así el colapso del sistema sanitario provocado por la alta demanda de pacientes.

La mejor estrategia de prevención es el futuro desarrollo de una vacuna efectiva contra el virus, idealmente en esquema de una dosis y que se pueda producir en masa a bajo costo, considerando que a futuro puede convertirse en una enfermedad estacional como la influenza. El foco actual está en desarrollar anticuerpos contra la espiga de la proteína de superficie donde se pueden ensayar diferente plataformas como virus vivo atenuado o plasmidios DNA o RNA mensajero que codifique proteínas virales que estimulen anticuerpos neutralizantes.

Como humanidad hemos logrado superar muchas pandemias, sin duda saldremos exitosos de esta, tal vez en uno o dos años, sin embargo ¿qué pasará al final de la pandemia?, ¿volveremos a ser los mismos?, ¿cambiarán nuestras prioridades? ¿podré abrazar a mis hijos y a mi nieto sin temor?

\section{Conflicto de intereses}

El autor declara no tener conflicto de intereses.

\section{Referencias}

1. Tyrrell DA, Bynoe ML. Cultivation of viruses from a high proportion of patients with colds. Lancet. 1966;1:76-7.

2. UCSC Genome Browser on SARSCoV-2 Jan. 2020 (ASM985889v3/SARSCoV-2 Assembly (wuhCor1) [accedido el 28 de marzo de 2020] Disponible en https://genome.ucsc.edu/cgi-bin/ hgTracks?db=wuhCor 1 .
3. Zou L, Ruan F, Huang $M$ et al. SARSCoV-2 Viral Load in Upper Respiratory Specimens of Infected Patients. New Eng J Med 2020;382:12.

4. van Doremalen N, Bushmaker T, Morris $\mathrm{DH}$, et al. Aerosol and Surface Stability of SARS-CoV-2 as Compared with SARSCoV-1. New Eng J Med. 2020; [ahead of print].

5. Canals M. Proyección de la demanda de camas UCI (datos hasta el 25 de marzo 2020). [accedido el 28 de marzo de 2020]. Disponible en: http://www.saludpublica.uchile.cl/ noticias/162173/proyeccion-de-lademanda-de-camas-uci-datos-hastael-2503-2020.

6. Li R, Pei S, Chen B, et al Substantial undocumented infection facilitates the rapid dissemination of novel coronavirus (SARS-CoV2) Science 2020; 10.1126/ science.abb3221. 